\title{
I-Ceul recognition sites in the rrn operons of the Bacillus subtilis 168 chromosome: inherent landmarks for genome analysis
}

\author{
Tsutomu Toda ${ }^{1}$ and Mitsuhiro Itaya ${ }^{2}$ \\ Author for correspondence: Mitsuhiro Itaya. Tel: +81 42724 6254. Fax: +81 427246316.
}

1 School of Science and
Engineering, Saitama
University, Urawa-shi,
Saitama 338, Japan
2 Mitsubishi Kasei Institute
of Life Sciences, 11
Minamiooya, Machida-shi,
Tokyo 194, Japan

\begin{abstract}
The Bacillus subtilis 168 circular chromosome yielded ten fragments on I-Ceul endonuclease digestion. I-Ceul recognizes a 26 bp sequence that is located within the gene encoding the 235 subunit of the rRNA in Chlamydomonas eugametos, Escherichia coli and Salmonella typhimurium. The precise locations of the I-Ceul sites of the B. subtilis chromosome were determined on a Notl-Sfil physical map by (i) double digestion analyses with I-Ceul and Sfil, (ii) comparison of mutant strains lacking a specific rrn operon, (iii) using an I-Ceul linking clone and (iv) analysis of nucleotide sequence data of some $r m$ operons. In conclusion, all the I-Ceul sites were located within the B. subtilis rrn operons and the I-Ceul sites were conserved in all the B. subtilis 168 derivatives tested. Thus, variations in size of the l-Ceul fragments must be due to genome alterations. A B. subtilis 168 strain was investigated with I-Ceul. We demonstrated that the aberrant structure was the outcome of the inversion of an $1700 \mathrm{~kb}$ DNA segment.
\end{abstract}

Keywords: I-CeuI, rrn operons, Bacillus subtilis, inversion, genome analysis

\section{INTRODUCTION}

International cooperative sequencing projects for genomes of a few prokaryotes, Escherichia coli, Mycobacterium leprae, Mycoplasma genitalium and Bacillus subtilis are now in progress (Kunst et al., 1995). The information of the entire nucleotide sequence for these microorganisms is expected to reveal many aspects of a unified as well as the diverse nature of the bacterial chromosome. In addition to understanding the genome structure of standard strains, studies on the variation of genomes within a given species are equally important.

A detailed physical map for a standard B. subtilis strain was constructed, namely a restriction map by two type II restriction endonucleases, Not I and SfiI (Itaya \& Tanaka, 1991). Some DNA alterations, mostly deletion mutations, have been characterized based on the physical map (Itaya et al., 1992; Itaya, 1993a).

A new class of sequence-specific endonucleases was recently discovered. These 'homing endonucleases' are classified as enzymes whose catalytic activity results in self-propagation. A number of such enzymes have been found and their biochemical and genetic characterization

Abbreviation: CHEF, contour-clamped homogeneous electric field. has revealed their functional roles in species diversity and evolution (Mueller et al., 1993).

Homing endonucleases have potential for analysis of large genomes because their unique recognition sequences are usually composed of more nucleotides than those for type II restriction endonucleases. For example, I-SceI, isolated from Saccharomyces cerevisiae, recognizes a unique $18 \mathrm{bp}$ sequence (Mueller et al., 1993). As the $4188 \mathrm{~kb}$ B. subtilis chromosome has no intrinsic I-SceI recognition sequences, the genome can be segmented on I-SceI digestion only when novel I-SceI sites have been created in the chromosome. Antibiotic resistance genes carrying an I-SceI site were designed to be integrated into the $B$. subtilis chromosome, resulting in creation of these sites (Itaya $e t$ al., 1992; Itaya, 1992, 1993a, b, 1994). However, problems occur when the antibiotic resistance genes, namely the ISceI sites, cannot be integrated into the genome of transformation-deficient $B$. subtilis strains. This is probably the case for other rare-cutting endonucleases.

As cognate inherent landmarks on the B. subtilis chromosome were desirable for in-depth genome analyses, we tested other homing endonucleases, I-PpoI (from Physarum polycephalum), VDE (Sacc. cerevisiae), I-TliI (Thermococcus litoralis), and I-CeuI (Chlamydomonas eugametos). Only I-CeuI cleaved the B. subtilis genome and yielded ten fragments reproducibly. 
Table 1. Bacterial strains and plasmids used in this study

\begin{tabular}{|c|c|c|}
\hline Strain or plasmid & Genotype & Reference \\
\hline \multicolumn{3}{|l|}{ B. subtilis } \\
\hline $168 \operatorname{trp} C 2(=1 \mathrm{~A} 1)$ & $\operatorname{trp} C 2$ & Itaya (1993a) \\
\hline BEST2076* & $1 \mathrm{~A} 1$ plus $\operatorname{ter} C::$ neo $\left(\mathrm{I}-S_{c e} \mathrm{I}\right) \operatorname{rec} F:: \operatorname{cat}\left(\mathrm{I}-S_{c e} \mathrm{I}\right)$ & Itaya (1993a) \\
\hline BEST3015 & leuB7 $\arg \Delta(r r n J-r r n W)$ & Itaya (1993c) \\
\hline BD170 & $\operatorname{trp} C 2 \operatorname{tbr}-5 \Delta(r r n H-r r n G)$ & Itaya (1993c) \\
\hline \multirow[t]{2}{*}{60015} & $\operatorname{met} C 7 \operatorname{trp} C 2$ & Itaya (1993a) \\
\hline & & Freese \& Fortnagel (1967) \\
\hline \multirow[t]{2}{*}{60866} & 60015 plus inv(C/S) $\Delta i g f \Delta(r r n H-r r n G)$ & Freese \& Fortnagel (1967) \\
\hline & & Fujita \& Freese (1981) \\
\hline YF001 & $\operatorname{trp} C 2 \operatorname{met} B 5$ bis $A 1$ leu- 8 attSPB $\Delta$ skin $\operatorname{Not} \mathrm{I}(20 \mathrm{~N} / 21 \mathrm{~N}) \dagger$ & Fujita \& Freese (1981) \\
\hline $61656 \neq$ & YF001 plus $\Delta i g f$ & Fujita \& Freese (1981) \\
\hline \multicolumn{3}{|l|}{ E. coli } \\
\hline JA221 & $\mathrm{F}^{-} b s d \mathrm{R} b s d M^{+} \operatorname{trp} \operatorname{leu} \operatorname{lac} Y \operatorname{rec} A 1$ & Itaya \& Tanaka (1991) \\
\hline \multicolumn{3}{|l|}{ E. coli plasmid $\sqrt{ }$} \\
\hline pCENT1 & $2.3 \mathrm{~kb}$ EcoRI carrying part of the $r r n G$ & This study \\
\hline pNEXT38 & NotI-linking clone at $786 \mathrm{~kb}$ & \\
\hline pNEXT49 & NotI-linking clone at $140 \mathrm{~kb}$ & \\
\hline pNEXT53 & Not I-linking clone at $13 \mathrm{~kb}$ & \\
\hline pNEXT59 & Not I-linking clone at $483 \mathrm{~kb}$ & \\
\hline pNEXT55 & NotI-linking clone at $3142 \mathrm{~kb}\}$ & Itaya \& Tanaka (1991) \\
\hline pSOFT1 & Sfil-linking clone at $1045 \mathrm{~kb}$ & \\
\hline pSOFT8 & Sfit-linking clone at $675 \mathrm{~kb}$ & \\
\hline pSOFT11 & SfiI-linking clone at $4055 \mathrm{~kb}$ & \\
\hline pSOFT15 & Sfil-linking clone at $2542 \mathrm{kbg}$ & \\
\hline
\end{tabular}

* I-SceI sites were integrated in the recF and $\operatorname{ter} C$ region, resulting in two fragments, 2192 and $1996 \mathrm{~kb}$, on I-SceI digestion (Itaya, 1993a). † A NotI site between $20 \mathrm{~N}$ and $21 \mathrm{~N}$ was lost (Itaya \& Tanaka, 1991).

$\ddagger 61656$ was isolated as a pur $A$ transductant to which the igf mutation was transmitted.

$\S$ Location of the insert of the pNEXT and pSOFT series was previously described by Itaya \& Tanaka (1991).

$\mathrm{g}$ Corrected position (unpublished data).

I-CeuI recognizes and cleaves a 26 nucleotide sequence, $5^{\prime}$ TAACTATAACGGTCCTAAGGTAGCGA- ${ }^{\prime}$, and is encoded by a group I intron in the large subunit rRNA gene of $C$. eugametos (Marshall et al., 1994). Liu et al. (1993a, b) reported that I-CeuI recognized and cleaved the sites within the $r r n$ operons of the genomes of Salmonella typhimurium, E. coli and other bacteria. The 26 bp sequence was found in the 23S rRNA gene of the B. subtilis $r r n B$ operon (Green et al., 1985), the only $r r n$ operon whose nucleotide sequence had been determined when our work was initiated. We predicted that I-CeuI cleavage sites may be located in all ten $r r n$ operons of the $B$. subtilis chromosome because the nucleotide sequences of $r r n$ genes are highly conserved among distantly related species (Woese et al., 1990).

In this paper we demonstrate experimentally that all $B$. subtilis rrn operons have an I-CeuI site, and this allowed the precise mapping of all the $r r n$ genes on the NotI-SfI physical map. We also report that the inherent I-CeuI sites are suitable for analysing DNA rearrangements particularly those of strains lacking transformability. In an experiment using I-CeuI combined with NotI and SfiI, we showed that a previously unidentified DNA aberration is an $\sim 1700 \mathrm{~kb}$ inversion.

\section{METHODS}

Bacterial strains and plasmids. Bacterial strains and plasmids used in this study are listed in Table $1 . B$. subtilis $168 \operatorname{trp} C 2$ was from the Bacillus Genetic Stock Center (Columbus, OH, USA). The SfiI-NotI physical map has been previously reported (Itaya \& Tanaka, 1991). Its brief description is given in the legend to Fig. 4. Preparation and transformation of E. coli JA221 competent cells were done by the method of Mandel \& Higa (1970). LB broth (Miller, 1972) was used for growth of E. coli and $B$. subtilis. Nutritional requirements for $B$. subtilis were tested using Spizizen medium supplemented with appropriate amino acids ( $5 \mu \mathrm{g} \mathrm{ml}^{-1}$; Spizizen, 1958). Bacteria were grown at $37^{\circ} \mathrm{C}$. All the plasmids were purified by $\mathrm{CsCl} /$ ethidium bromide ultracentrifugation.

In vitro DNA manipulations. Type II restriction enzymes and T4 DNA ligase were obtained from Toyobo, except for SfI (New England Biolabs) and NotI (Takara Shuzo). Homing 

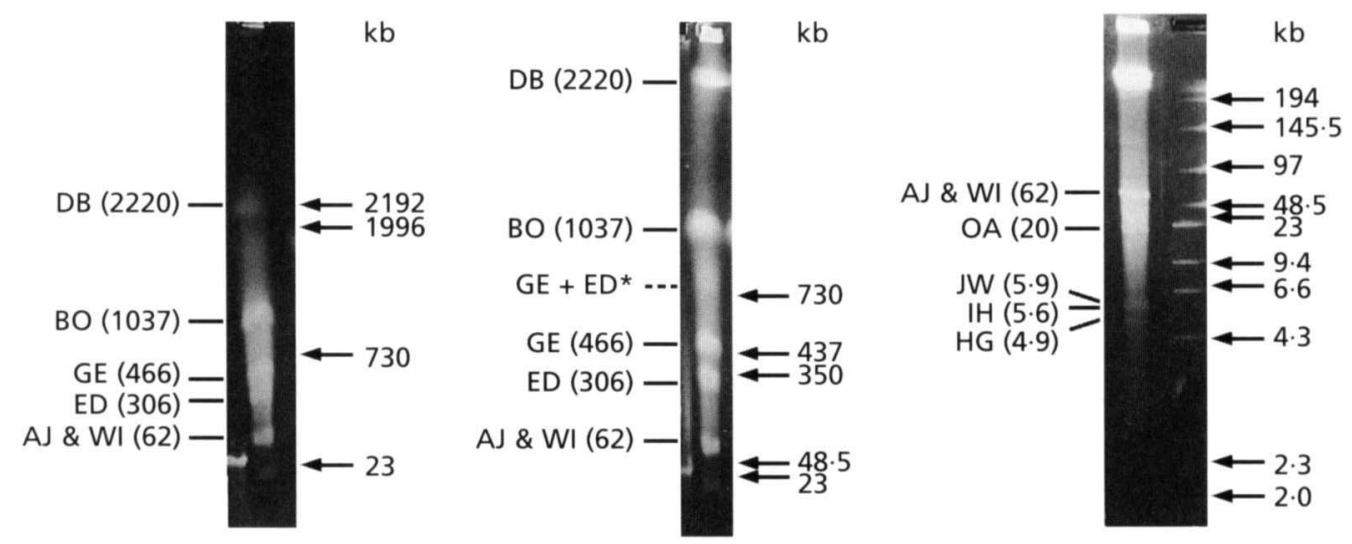

Fig. 1. Separation of the I-Ceul fragments of the B. subtilis 168 trpC2 chromosome. I-Ceul digests of about 2-3 $\mu \mathrm{g}$ DNA from $B$. subtilis $168 \operatorname{trpC2}$ were separated by CHEF gel electrophoresis. Pulse time and running time adopted to obtain good resolution for different size ranges: left, $8 \mathrm{~min}$ and $44 \mathrm{~h} ;$ middle, $3 \mathrm{~min}$ and $44 \mathrm{~h} ;$ right, $18 \mathrm{~s}$ and $32 \mathrm{~h}$. Other conditions were as described in Methods except for $4 \mathrm{~V} \mathrm{~cm}^{-1}$ (right). I-Ceul fragments were designated by two capital letters with their estimated size in parentheses. Capital letters represent the last letter of the respective rrn operon (Figs 2,4 and 6). The asterisked fragment was generated by partial digestion at a poorly cleavable I-Ceul site between GE and ED (see text for details). Intensities of larger bands in the left panel are small compared with their expected amounts, probably due to non-specific cleavage during DNA preparation and enzyme digestion. Size markers of 2192 and $1996 \mathrm{~kb}$ were the digests of BEST2076 with I-Scel (Table 1). Sizes of 730, 437 and $350 \mathrm{~kb}$ were the Sfil digests of B. subtilis 168 $\operatorname{trpC2}$. Size markers for 48.5-194 kb were concatemeric $\lambda$ DNA oligomers. Size markers below $23 \mathrm{~kb}$ were from $\lambda$ DNA digested with HindIII.

endonucleases I-SceI, I-CeuI, VDE, I-TliI and I-PpoI were purchased from NEB. DNA manipulations in vivo were done according to standard procedures (Maniatis et al., 1982) or the manufacturers' instructions unless specified. DNA in gel blocks after digestion with I-CeuI was treated with proteinase $\mathrm{K}$ for $1 \mathrm{~h}$ at $37^{\circ} \mathrm{C}$ to obtain sharp bands as suggested by the manufacturer.

Preparation of B. subtilis chromosomal DNA. B. subtilis chromosomal DNA for contour-clamped homogeneous electric field (CHEF) gel electrophoresis was prepared in agarose plugs as described previously (Itaya \& Tanaka, 1991). Agarose gel $(1.0 \%, w / v)$ in TBE solution [45 mM Tris/borate ( $\mathrm{pH} \mathrm{8.0)}$, 1.0 mM EDTA] was used for CHEF gel electrophoresis under constant voltage of $3 \mathrm{~V} \mathrm{~cm}^{-1}$ at $14{ }^{\circ} \mathrm{C}$ unless otherwise specified. Other running conditions are described in the figure legends. After electrophoresis, DNAs were stained in ethidium bromide solution $\left(600 \mathrm{ng} \mathrm{ml}^{-1}\right)$ for $15 \mathrm{~min}$, photographed and subjected to Southern analysis.

Two-dimensional CHEF gel electrophoresis. After CHEF gel electrophoresis, gel blocks containing SfiI (or I-CeuI) fragments were excised by monitoring under $310 \mathrm{~nm}$ UV light and washed at least three times in $0.5 \mathrm{ml} \mathrm{TE}$ solution $[10 \mathrm{mM}$ Tris $/ \mathrm{HCl}$ ( $\mathrm{pH} 7.5), 1.0 \mathrm{mM}$ EDTA] for $15 \mathrm{~min}$. The gel blocks were immersed in the reaction buffer $(0.2-0.8 \mathrm{ml})$ in $2.0 \mathrm{ml}$ Eppendorf tubes, and digested with the second enzyme, I-CeuI (or SfiI).

Isolation of an I-Ceul-linking clone. Plasmids carrying an ICeuI site (I-CeuI-linking clone) were obtained from a $B$. subtilis EcoRI DNA library made on pBEST504 (Itaya \& Tanaka, 1991). The DNA library (about $10 \mu \mathrm{g}$ ) was digested in $100 \mu \mathrm{l}$ with one $\mathrm{U}$ of $\mathrm{I}-\mathrm{CeuI}$ for $2 \mathrm{~h}$. The digests were incubated at $65^{\circ} \mathrm{C}$ for $10 \mathrm{~min}$ before loading in wells to denature ingredient proteins. Without denaturation, I-CeuI digests run with poor resolution (unpublished observations). Linearized plasmid fractions (equivalent to linearized I-CeuI linking clones) were separated and purified from closed circular plasmids by $\mathrm{CHEF}$ gel electrophoresis under the following conditions: $10 \mathrm{~V} \mathrm{~cm}^{-1}$,
$120 \mathrm{~s}$ pulse time, $3 \mathrm{~h}$ run at $14^{\circ} \mathrm{C}$ in $2 \%$ low-melting-point agarose (type VII; Sigma) in TBE solution. The linearized DNAs were used to transform JA221 after ligation. Plasmid DNAs from the ampicillin- and chloramphenicol-resistant transformants were analysed. A linking clone was obtained and designated pCENT1. pCENT1 hybridized to all the I-CeuI fragments (data not shown) and it also hybridized to four SfiI fragments (BS, CS, FS and MS) and five NotI fragments ( $7 \mathrm{~N}$, $9 \mathrm{~N}, 13 \mathrm{~N}, 24 \mathrm{~N}$ and $27 \mathrm{~N}$ ) (data not shown). The SfiI and NotI fragments were identical to those that hybridized with an $r r n O$ probe in separate experiments (Itaya, 1993c), indicating that the $2.3 \mathrm{~kb}$ EcoRI insert of pCENT1 was derived from a $B$. subtilis rrn operon. Its size allowed us to assign it unequivocally to part of the $r r n G$ operon as indicated in Fig. 2 (Rudner et al., 1993). pCENT1 was used as a representative for I-CeuI linking clones in this study.

Southern hybridization and DNA probes. DNA in agarose gels was transferred onto nylon membranes (Nytran 13N; Shleicher \& Schuell) by capillary blotting for 15-17 h (Southern, 1975). A non-radioactive labelling nucleotide, digoxigenin-11-dUTP, was used for preparing DNA probes. The random primer labelling technique, pre-hybridization and hybridization procedures and colour development were according to the protocol of the DNA Labelling and Detection Kit (Boehringer Mannheim).

\section{RESULTS AND DISCUSSION}

Digestion of genomic DNA of $B$. subtilis $168 \operatorname{trpC} 2$ with I-CeuI yielded ten fragments (Fig. 1). Preliminary double digestion analysis of the $B$. subtilis chromosome with SfiI and I-CeuI indicated that I-CeuI sites were located on the BS, CS, MS, and FS fragments (data not shown). To determine the location of I-CeuI sites in these four SfiI fragments, the respective SfiI fragment was isolated and 

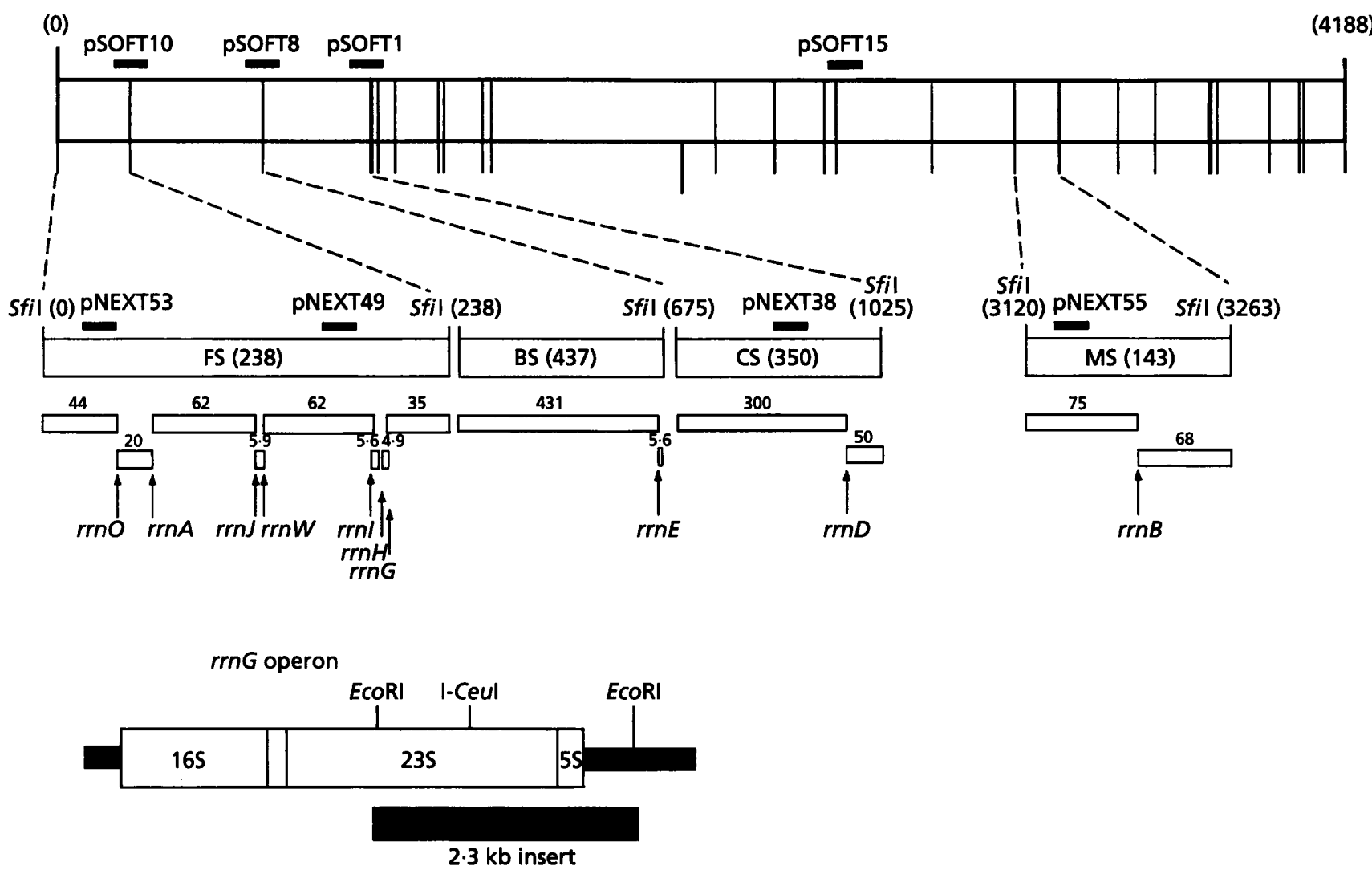

Fig. 2. Location of I-Ceul sites on the rrn operons of the B. subtilis chromosome. Top: The $4188 \mathrm{~kb}$ Sfil restriction map of the B. subtilis 168 trpC2 strain (Itaya \& Tanaka, 1991, 1993a) was drawn in linear form. Middle: The FS, BS, CS and MS fragments were enlarged with their sizes in the parentheses. Scales are not uniform. Positions of the Sfil sites of interest are underlined. Fragments obtained by I-Ceul digestion from the respective Sfil fragments are shown with their estimated sizes. Data are shown in Fig. 3. Locations for Sfil-linking clones (pSOFT\#) or Notl-linking clones (pNEXT\#) are indicated with closed bars (see Table 1). They were used as probes to assign the fragments shown in Figs 3 and 5 . Bottom: structure of the rrnG operon and its flanking chromosomal regions (closed area) redrawn from Widom et al. (1988). The $2.3 \mathrm{~kb}$ EcoRI insert (shaded box) cloned in pCENT1 includes most of the 235 gene, the 55 gene, and part of another chromosome area.

re-digested with I-CeuI. The strategy is presented in Fig. 2.

\section{I-Ceul sites in the BS, CS and MS fragments}

I-CeuI digestion of the isolated BS, CS or MS fragments gave two sub-fragments. In brief, $\mathrm{BS}(437 \mathrm{~kb})$ was cleaved to a 431 and a $5.6 \mathrm{~kb}$ fragment (Fig. 3c), CS $(350 \mathrm{~kb})$ to a 300 and a $50 \mathrm{~kb}$ fragment (Fig. $3 \mathrm{a})$, and MS (143 kb) to a 75 and a $68 \mathrm{~kb}$ fragment (Fig. 3e). The size of the subfragments should correspond to the distance from the nearest SfiI site (Fig. 2). The order of the two subfragments was determined by using specific positional probes as indicated in Fig. 2: pSOFT10 and pSOFT8 for BS (Fig. 3d), pSOFT8, pNEXT38, and pSOFT1 for CS (Fig. 3b), and pNEXT55 for MS (Fig. 3f). The results are shown in Fig. 2. All the shortened fragments were hybridized with pCENT1 (data for the CS fragment only is shown in lane 3 of Fig. 3b).

The results were consistent with there being a I-CeuI site in the $23 \mathrm{~S}$ gene of all $r r n$ operons. The unequivocally determined positions of these I-CeuI sites were at a distance of $669 \mathrm{~kb}$ ( $r r n E$ in the BS fragment), $975 \mathrm{~kb}$ ( $r n D$ in the CS fragment) and $3195 \mathrm{~kb}(r r n B$ in the MS fragment) (Fig. 4).

\section{Seven I-Ceul sites in the FS fragment}

The isolated FS fragment yielded eight sub-fragments on I-CeuI digestion, a $33 \mathrm{~kb}$ and a $44 \mathrm{~kb}$ fragment in addition to the six originally found (Fig. $3 \mathrm{~h}$ ). This indicated that there were seven I-CeuI sites inside the FS fragment. Itaya (1993c) already demonstrated that seven $r r n$ operons were located in the FS fragment. It was therefore most likely that these seven I-CeuI fragments belong to the seven rrn operons. This was demonstrated by the following experiments.

Two $B$. subtilis mutant strains that have lost a segment between two tandemly repeated $r r n$ operons have been obtained. They are BEST3015 and BD170 (Table 1), having a deletion from $r r n J$ to $r r n W$ and from $r r n G$ to $r r n H$, respectively (Itaya, 1993a, c). Thus, I-CeuI digestion of the DNA of these mutants should reveal the loss of the respective I-CeuI fragments, and indeed this was the case 

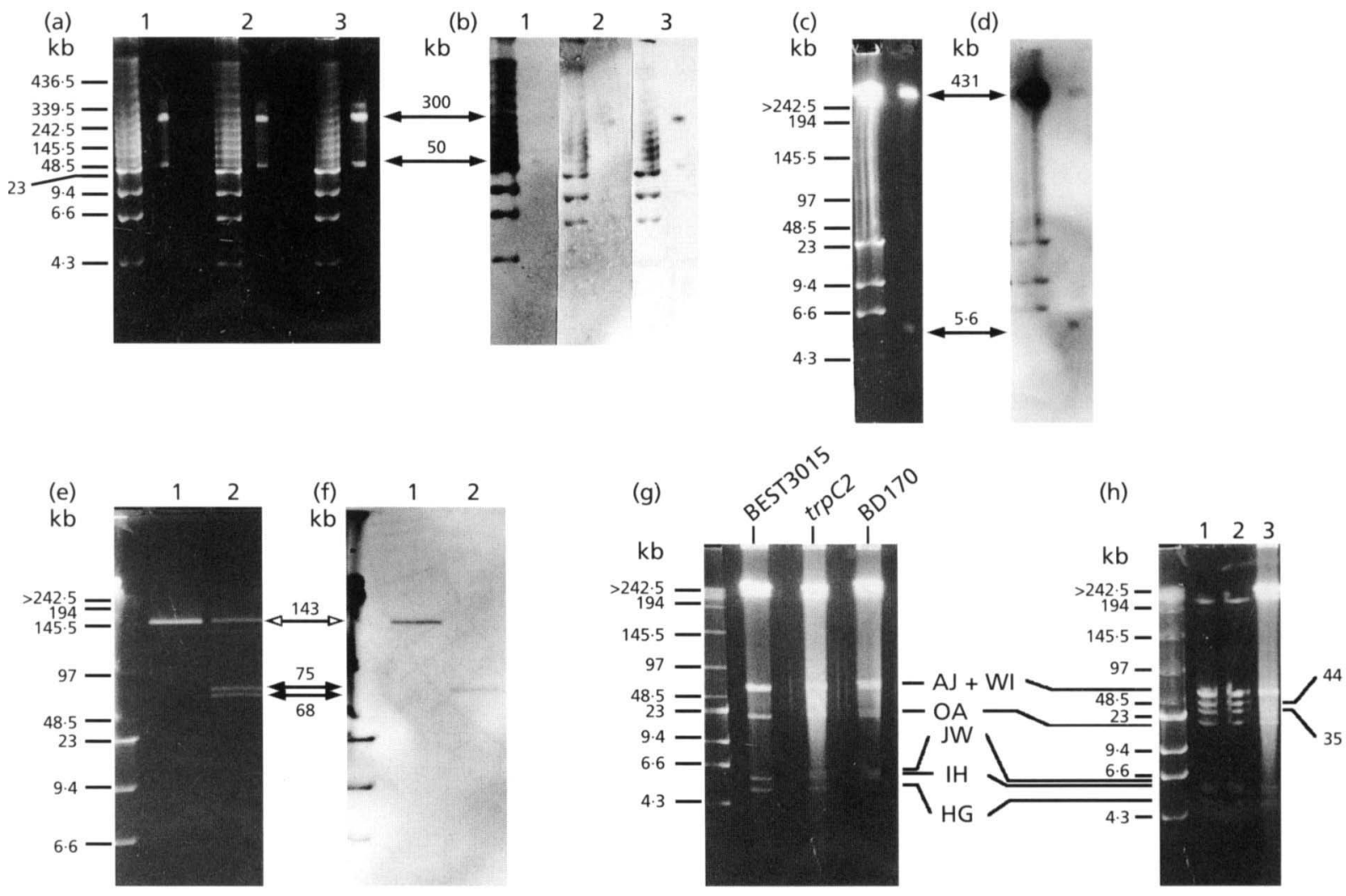

\begin{abstract}
Fig. 3. Location of I-Ceul sites in Sfil fragments. Isolated Sfil fragments were digested with I-Ceul and the resulting fragments were separated by CHEF gel electrophoresis. Size markers for $48.5-463.5 \mathrm{~kb}$ were concatemeric $\lambda$ DNA oligomers. Size markers below $23 \mathrm{~kb}$ were $\lambda$ DNA digested with HindIII. Probes used are indicated in Fig. 2 and Table 1. (a) The $350 \mathrm{~kb}$ CS fragment was cleaved to a 300 and a $50 \mathrm{~kb}$ fragment indicated by arrows. Pulse and running times: $60 \mathrm{~s}$ and $20 \mathrm{~h}$. (b) The $50 \mathrm{~kb}$ fragment was hybridized with pSOFT1 (lane 1). pNEXT38 hybridized to the $300 \mathrm{~kb}$ fragment (lane 2). pCENT1 (rrnG) hybridized with both fragments (lane 3). (c) The $437 \mathrm{~kb}$ BS fragment was cleaved to 431 and $5.6 \mathrm{~kb}$. Pulse and running times: $12 \mathrm{~s}$ and $16 \mathrm{~h}$. Voltage was constant at $4 \mathrm{~V} \mathrm{~cm}^{-1}$. (d) The $5.6 \mathrm{~kb}$ fragment was hybridized with pSOFT8. The slight hybridization of pSOFT to the $431 \mathrm{~kb}$ fragment was due to partial digestion of this l-Ceul site (see text). (e) The $143 \mathrm{~kb}$ MS fragment (lane 1) was cleaved to a 75 and a $68 \mathrm{~kb}$ fragment (lane 2). Pulse and running times: $12 \mathrm{~s}$ and $40 \mathrm{~h}$. Voltage was constant at $2 \cdot 7 \mathrm{~V} \mathrm{~cm}^{-1}$. Open-headed arrows indicate the LS fragment (143 kb) and a small amount of the NS fragment $(133 \mathrm{~kb})$ that were co-purified with the MS fragment and left unchanged in lane 2. ( $f$ ) pNEXT55 hybridized to the $75 \mathrm{~kb}$ fragment. (g) Chromosomal DNA from BEST3015, 168 trpC2 and BD170 was run after ICeul digestion. Pulse and running times: $12 \mathrm{~s}$ and $15 \mathrm{~h}$. Voltage was constant at $4 \mathrm{~V} \mathrm{~cm}^{-1}$. The $5.9 \mathrm{~kb}$ (JW) and $4.9 \mathrm{~kb}$ (HG) fragments were lost in BEST3015 and BD170, respectively. See text for details. (h) Lanes 1 and 2, the purified FS fragment cleaved to eight bands on I-Ceul digestion. Chromosomal DNA from strain 168 trpC2 was run after I-Ceul digestion in lane 3. Pulse and running times: $12 \mathrm{~s}$ and $15 \mathrm{~h}$. Voltage was constant at $4 \mathrm{~V} \mathrm{~cm}^{-1}$. The internal six bands (A), WI, OA, JW, IH and HG) were unchanged in all lanes. Two new bands ( $44 \mathrm{~kb}$ and $35 \mathrm{~kb}$ ) in lanes 1 and 2 were assigned to the distal ends of the FS fragment (Fig. 2) by using the specific probes PNEXT53 or pSOFT10 (data not shown).
\end{abstract}

(Fig. 3g). The smallest, $4.9 \mathrm{~kb}$, fragment that was lost in BD170 was readily assigned to the segment between $r r n H$ and $r r n G$. Similarly, the $5.9 \mathrm{~kb}$ fragment that was lost in BEST3015 was assigned to the segment between $r r n J$ and $r r n W$. The $5 \cdot 6 \mathrm{~kb}$ fragment was automatically assigned to the segment between $r r n I$ and $r r n H$ (Widom et al., 1988).

The location of the other fragments was determined with the position-specific probes shown in Fig. 2. The eight fragments were aligned (Fig. 2) and positioned on the physical map (Fig. 4).

The nucleotide sequence of the four $r r n$ operons in the $9 \mathrm{~N}$ fragment $(r r n \mathrm{O}, r r n A, r r n J$, and $r r n W)$ was recently determined (Ogasawara et al., 1994, 1995) and the I-CeuI recognition sequence was found in all four $23 \mathrm{~S} \mathrm{rDNA}$ genes. The $26 \mathrm{bp}$ of $r r \mathrm{O}, r r n A, r r n J, r r n W$ (Ogasawara $e t$ al., 1994) and $r r n B$ (Green et al., 1985) are identical to the recognition site reported for the $\mathrm{rr} /$ gene from $C$. eugametos (Marshall et al., 1994).

It should be noted that complete cleavage at the I-CeuI site of $r n E$ could not be achieved in various digestion conditions; it resulted in small amounts of the uncleaved GE + ED fragment (see legend to Fig. 1). Poor cleavage sites were not found in S. typhimurium or in E. coli (Liu et al., 1993a). Although the reason for a poor cleavage site at $r r n E$ is not fully understood, it could be due to a degenerated sequence or to an as yet unidentified DNA modification in the recognition site (Mueller et al., 1993). 


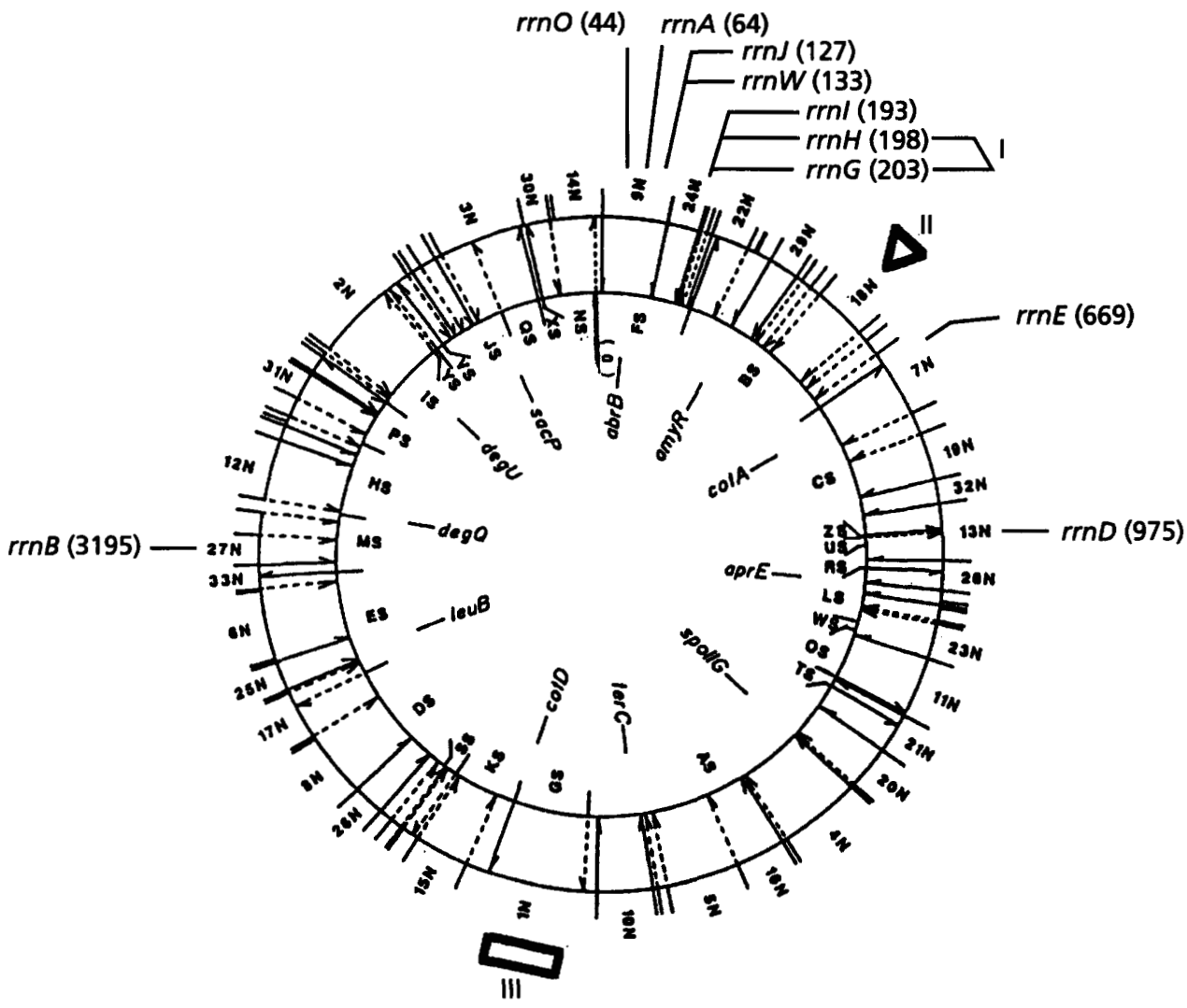

Fig. 4. Location of the rrn operons on the B. subtilis Sfil-Notl physical map. The Notl-Sfil physical map (Itaya \& Tanaka, 1991) was redrawn with minor modifications. Briefly, 26 Sfil fragments (AS-ZS) were aligned in the inner circle and 72 Notl fragments ( $1 \mathrm{~N}-33 \mathrm{~N}$ and smaller) in the outer circle. The Sfil site between fragments FS and NS was designated as the zero point of the $4188 \mathrm{~kb}$ map. Physical distance (in $\mathrm{kbp}$ ) of the rrn operons are in parentheses. I, II and III, spontaneous deletions previously characterized by Itaya (1993a). See text for details.

The I-CeuI recognition sequences are well-conserved in all $B$. subtilis 168 derivative strains tested to date. For example, three spontaneous DNA deletions frequently formed at three different regions of the B. subtilis 168 chromosome were analysed (Fig. 4). The smallest deletion, designated deletion I (Itaya, 1993a), was identical to that of the HG (I-CeuI) fragment observed in BD170. A $23 \mathrm{~kb}$ deletion that occurred in the BS (Sfi) fragment, designated deletion II, was found to be a $23 \mathrm{~kb}$ decrease in the GE (I-Ceul) fragment (data not shown). The mechanism for the formation of deletion II is not clear. An $130 \mathrm{~kb}$ deletion associated with the excision of the SP $\beta$ prophage occurring in the GS (SfiI) fragment (designated deletion III in Fig. 4) agrees with a $130 \mathrm{~kb}$ decrease in size of the DB (I-CeuI) fragment (data not shown). I-CeuI sites are, thus, inherent stable landmarks of the B. subtilis 168 chromosome and can be an immediate tool for structural analysis of the genome.

\section{Use of I-Ceul to detect a chromosome DNA inversion}

B. subtilis strain 60866 , a sporulation- and transformationdeficient mutant, was isolated after ${ }^{60} \mathrm{Co}$ irradiation by Freese \& Fortnagel (1967). Fujita \& Freese (1981) later demonstrated that the mutant did not exhibit fructosebisphosphatase $(f d p)$ activity. Fujita \& Fujita (1983) characterized the mutation, designated $f d p A 1$, as a deletion spanning a large region including the iol, gnt and $f d p$ genes, and renamed it as $\Delta i g f$. Its parental strain, 60015 , had a chromosome structure identical to that of $168 \operatorname{trpC2}$ (Itaya, 1993a). In contrast, strain 60866 lacked four original SfiI fragments (CS, FS, NS and SS indicated in Fig. 5a, b) and at least three NotI fragments $(14 \mathrm{~N}, 19 \mathrm{~N}$ and $24 \mathrm{~N}$ ) (data not shown, but the location of these Not $\mathrm{I}$ fragments is indicated in Fig. 4).

A decrease in size of the FS and $24 \mathrm{~N}$ fragments was assigned to the $4.9 \mathrm{~kb}$ deletion between $r r n \mathrm{H}$ and $r r n G$ (Figs $5 \mathrm{~b}$ and 6 ).

A decrease in size of about $40 \mathrm{~kb}$ in the NS and $14 \mathrm{~N}$ fragments (Fig. 5a) was assigned to the deletion including the gnt gene (Itaya \& Tanaka, 1991). Thus, it was most likely that the $40 \mathrm{~kb}$ deletion corresponded to the $\Delta i g f$ mutation suggested by Fujita \& Fujita (1983).

As regards the CS and SS fragments, the size decrease for CS $(350$ to $270 \mathrm{~kb}$ ), and the size increase for SS (38 to $107 \mathrm{~kb}$ ) were identified in Southern hybridization experiments using pSOFT8 and pSOFT15 (data not shown). 

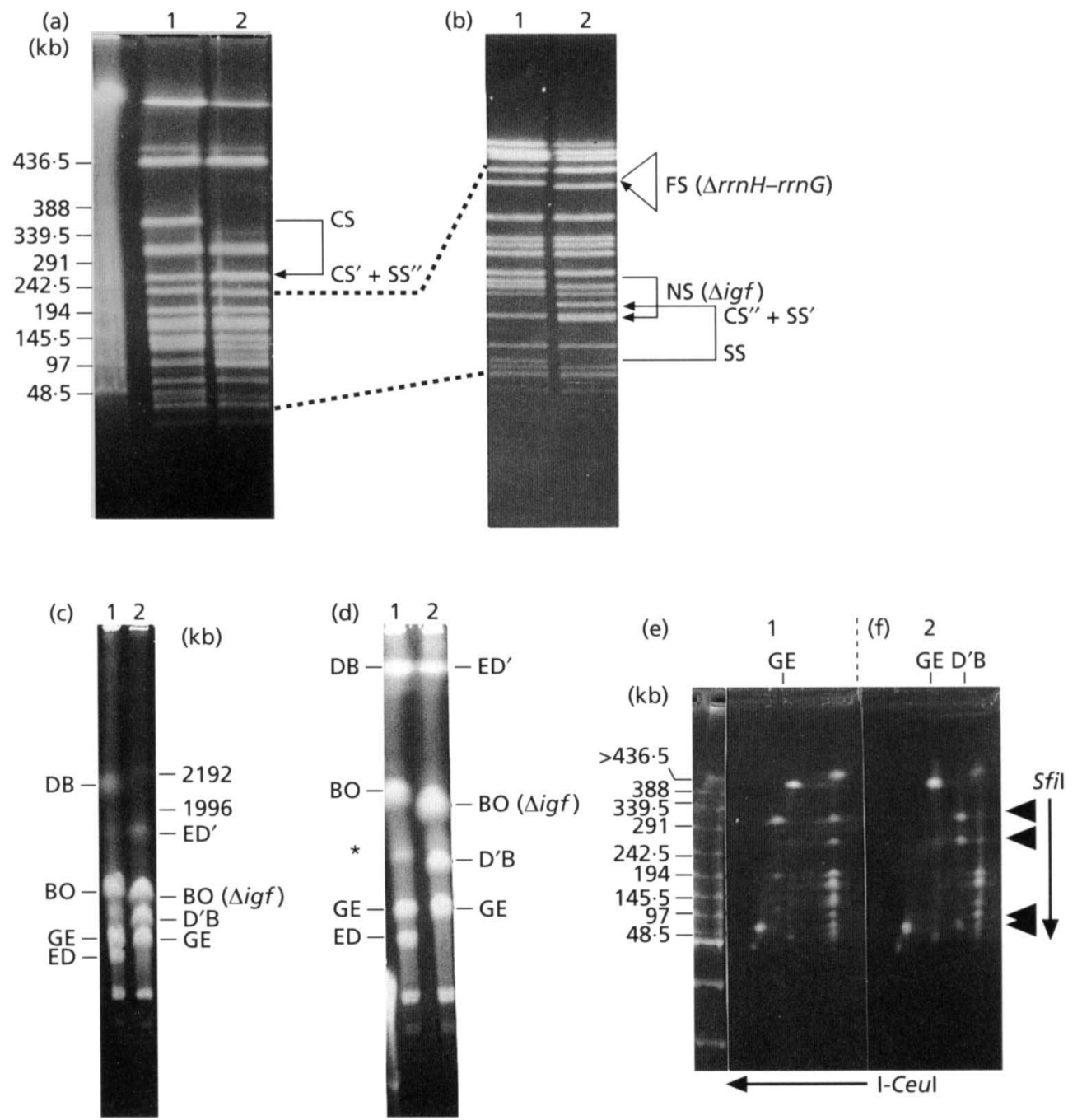

\begin{abstract}
Fig. 5. Altered fragments obtained from the $B$. subtilis strain having a chromosome DNA inversion. For all parts of the figure, chromosomal DNA from 168 trpC2 (1) or 60866 (2) was loaded. (a) and (b) Separation of Sfil fragments. Altered Sfil fragments (CS, FS, NS and SS) are indicated with their new positions on the right. For details see text and Fig. 6 . Pulse and running times were $60 \mathrm{~s}$ and $42 \mathrm{~h}$ for (a) and $24 \mathrm{~s}$ and $42 \mathrm{~h}$ for (b). Sfil fragments were well-resolved above $200 \mathrm{~kb}$ in (a), and below $250 \mathrm{~kb}$ in (b). (c) and (d) Separation of I-Ceul fragments greater and less than $1000 \mathrm{~kb}$, respectively. Fragments less than $62 \mathrm{~kb}$ were not detectable. Fragment designations in the 60866 lane are according to the structure of 60866 in Fig. 6. $D^{\prime}, r r n D^{\prime}$ operon of strain 60866 (see Fig. 6). Pulse and running times: 8 min and $44 \mathrm{~h}$ for (c) and $3 \mathrm{~min}$ and $44 \mathrm{~h}$ for (d). (e) and (f) I-Ceul fragments resolved in the first run (horizontal) were separated after Sfil digestion in the second run (vertical). The procedure for the second Sfil digestion is described in Methods. DB and BO fragments from $168 \operatorname{trpC2}$ or ED' and BO fragments from 60866 were not well separated in the first run under the running conditions. Thus, Sfil fragments from these two fragments appear to overlap in a single vertical lane in the right. Positions of the GE fragment from both strains and the D'B fragment from strain 60866 are indicated at the top. Four Sfil fragments should be obtained from the $D^{\prime} B$ fragment predicted by the 60866 structure shown in Fig. 6 . They are indicated by open arrowheads (from top): DS (310 kb), ES (268 kb), part of MS $(75 \mathrm{~kb})$ and an $\sim 70 \mathrm{~kb}$ fragment. The $75 \mathrm{~kb}$ fragment is the same as that in lane 2 of Fig. 3(f). The last $70 \mathrm{~kb}$ fragment comprised the SS" and CS" shown in Fig. 6 . Pulse and running times: $3 \mathrm{~min}$ and $14 \mathrm{~h}$ for the first run and $36 \mathrm{~s}$ and $36 \mathrm{~h}$ for the second run. Size markers of 2192 and $1996 \mathrm{~kb}$ in (c) were digests of BEST2076 with I-Scel (Table 1). Size markers for $48.5-463.5 \mathrm{~kb}$ were concatemeric $\lambda$ oligomers.
\end{abstract}

The nature of these two changes remained unknown with little information from the NotI or Sfil digestion analysis.

We examined the I-CeuI fragments obtained from the 60866 chromosome (Figs 5c, d). We observed three new fragments with altered sizes $\left(\mathrm{ED}^{\prime}, \mathrm{BO}\right.$ and $\left.\mathrm{D}^{\prime} \mathrm{B}\right)$ and concomitant loss of four original fragments $(\mathrm{DB}, \mathrm{BO}$, $\mathrm{ED}$, and $\mathrm{HG}$ ). Loss of the $4.9 \mathrm{~kb}$ HG fragment was consistent with the $r r n H-r r n G$ deletion as described above in the NotI and SfiI analysis (data not shown). An $40 \mathrm{~kb}$ decrease in size of the BO fragment was also consistent with the $\Delta i g f$ mutation (Figs $5 \mathrm{~d}$ and 6).

Results obtained from other altered I-CeuI fragments agreed only with the assumption that the alterations were due to an $\sim 1700 \mathrm{~kb}$ inversion indicated in Fig. 6. The 

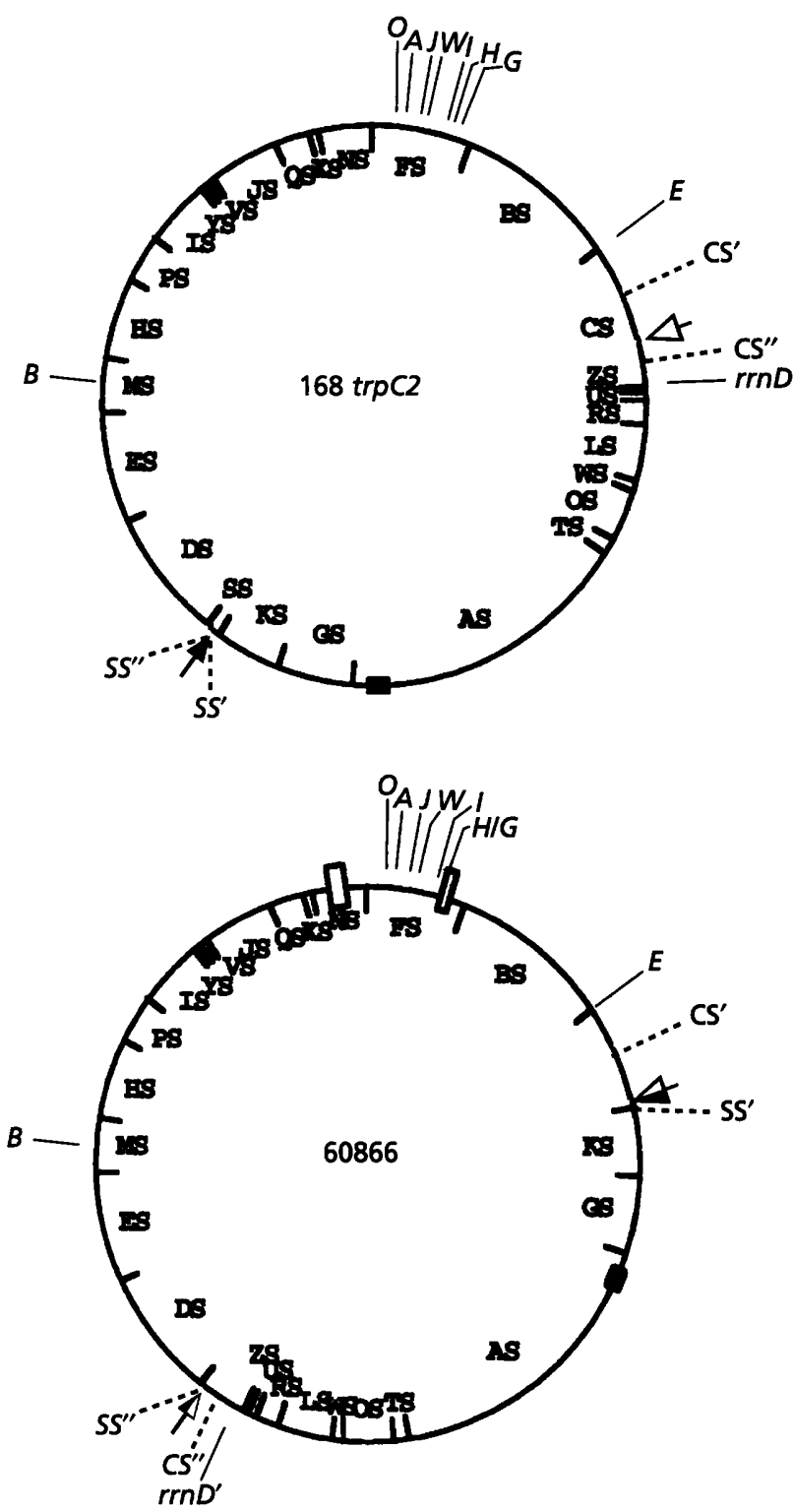

Fig. 6. Inversion of a $1700 \mathrm{~kb}$ DNA segment in strain 60866: Sfil physical maps for 168 trpC2 and 60866. rrn operons are designated by capital letters at their locations except for $r$ rnD for $168 \operatorname{trpC2}$ or $r r n D^{\prime}$ for 60866 . For 60866 , the open box in the FS fragment is a $4.9 \mathrm{~kb}$ deletion between $\mathrm{rrnH}$ and $\mathrm{rrnG}$ designated as $\mathrm{H} / \mathrm{G}$ and the open box in the NS fragment is an $~$ $40 \mathrm{~kb}$ deletion identified as the $\Delta i g f$ mutation (see text and Figs $5 b, d)$. The segment between two arrows in $168 \operatorname{trpC2}$ was inverted in the 60866 strain (C/S-type inversion). One end of the inversion is indicated by the open arrow in the CS fragment, and the other end by the closed arrow in the SS fragment. The recombined ends are shown by half-closed arrows in strain 60866. The CS fragment was divided into regions CS' and CS" at the end of the inversion. Similarly, the SS fragment was divided into SS' and SS". These regions were recombined in the 60866 strain. Closed box, the terC region.

inversion is hereafter designated as the C/S-type inversion because its endpoints reside in the CS and SS fragments. The C/S-type inversion transferred the $r r n D$ close to $r r n B$ and made it distant from the $r r n E$ (Fig. 6). The new location of the $r r n D$, putatively designated as the $r r n D^{\prime}$ of 60866 , resulted in a decrease in size of the DB fragment $\left(2220 \mathrm{~kb}\right.$ ) to $\mathrm{D}^{\prime} \mathrm{B}$ (about $750 \mathrm{~kb}$ ) and an increase in the size of the ED fragment $\left(306 \mathrm{~kb}\right.$ ) to $\mathrm{ED}^{\prime}$ (about $1750-1770 \mathrm{~kb}$ ) (Figs 5c, d and 6).

If the C/S-type inversion was true, the $\mathrm{D}^{\prime} \mathrm{B}$ fragment had to include four SfiI fragments. Three of them were the $\mathrm{DS}, \mathrm{ES}$ and the $75 \mathrm{~kb}$ fragment from the MS. The fourth included the $\mathrm{SS}^{\prime \prime}$ plus the $\mathrm{CS}^{\prime \prime}$ region distal to $r r n D^{\prime}$ (Fig. 6). These predicted fragments were obtained from the isolated $\mathrm{D}^{\prime} \mathrm{B}$ fragment on Sfi digestion as shown in Fig. 5(f). Similarly, the $\mathrm{ED}^{\prime}$ fragment included the 13 Sfi fragments predicted from the 60866 genome structure in Fig. 6 (data not shown).

One end of the inverted DNA region was located within the CS fragment, probably limited in the $19 \mathrm{~N}$ fragment (805-901 kb), because the NotI fragment was altered. The other end was positioned within the SS fragment (SfiI, 2481-2519) (Fig. 6). If the C/S-type inversion was caused by recombination at the two ends via equal crossing-over, the sum of the initial CS and SS fragments $(350+38=$ $388 \mathrm{~kb}$ ) should be equal to the sum of the recombined fragments, $\mathrm{CS}^{\prime}+\mathrm{SS}^{\prime}$ and $\mathrm{SS}^{\prime \prime}+\mathrm{CS}^{\prime \prime}$. However, the estimated size of the $\mathrm{CS}^{\prime}+\mathrm{SS}^{\prime}(268 \mathrm{~kb})$ and $\mathrm{SS}^{\prime \prime}+\mathrm{CS}^{\prime \prime}$ $(107 \mathrm{~kb}$ ) fragments (Fig. 5a, b) gave a sum of $375 \mathrm{~kb}$, indicating that about $13 \mathrm{~kb}$ were lost in 60866. The precise location of both endpoints and the lost region(s) remain to be demonstrated.

Are the sporulation and transformation-deficient phenotypes of strain 60866 due to DNA rearrangements? First, the $\Delta i g f$ deletion mutation of 60866 was accurately transmitted to 61656 by PBS1-mediated transduction without the accompanying C/S-type inversion (Table 1; data not shown). As strain 61656 is sporulation- and competent-proficient, it is unlikely that the $\Delta i g f$ mutation alone was the cause. Second, deletion of $r n G-r r n H$ alone had no effect on either phenotype, it only resulted in nine rrn operons left intact per B. subtilis chromosome (Itaya, 1993c). Third, reversed orientation of the ter $C$ region, termination of DNA replication (Yoshikawa \& Wake, 1993), seems detrimental to $B$. subtilis. Itaya (1994) reported a $1631 \mathrm{~kb}$-long DNA inversion between the met $(1255 \mathrm{~kb})$ and leuB $(2886 \mathrm{~kb})$ regions (designated as the BEST2145-type inversion). The BEST2145-type inversion that overlaps about $70 \%$ with the C/S-type inversion also made the $\operatorname{ter} C$ region inverted without causing sporulation and competence deficiency (Itaya, 1994). Thus, the reversed orientation of the ter $C$ region does not seem to be the cause. We suspect that the loss of about $13 \mathrm{~kb}$ in 60866 may be the reason, because the deletion(s) is specific for 60866 .

\section{Concluding remarks}

The finding of the C/S-type inversion was preceded by that of another long inversion associated with $\operatorname{trpE} 26$ mutation described by Anagnostopoulos and co-workers (designated here as the trpE26-type inversion: for a review see Anagnostopoulos, 1990). Jarvis et al. (1990) reported that the trpE26-type inversion was not induced 
via homologous recombination between hypothetical homologous regions on the $B$. subtilis chromosome, rather it was likely formed during the repair process after $\gamma$ irradiation. The C/S-type inversion likely occurred during the $\gamma$ irradiation (Freese \& Fortnagel, 1967) and, once established, was maintained stably in laboratory stocks. We think that long-range inversions do not occur normally (Itaya, 1993a), and speculate that unexpected inversion mutants could be found in strains isolated after $\gamma$ irradiation.

The I-CeuI sites on the B. subtilis chromosome were characterized and demonstrated to be inheritable. I-CeuI is now a useful tool for $B$. subtilis genome analysis in addition to NotI, Sfi and I-SceI. Attempts to create new ICeuI site(s) and/or elimination of I-CeuI sites from the $B$. subtilis chromosome are now being considered.

\section{ACKNOWLEDGEMENTS}

We thank Drs Naotake Ogasawara, Takehiko Shibata, Yasutaro Fujita and Yasuo Kobayashi for B. subtilis strains and discussions.

\section{REFERENCES}

Anagnostopoulos, C. (1990). Genetic rearrangements in Bacillus subtilis. In The Bacterial Chromosome, pp. 361-371. Edited by K. Drlica \& M. Riley. Washington, DC: American Society for Microbiology.

Freese, E. \& Fortnagel, P. (1967). Analysis of sporulation mutants. J Bacteriol 94, 1957-1969.

Fujita, Y. \& Freese, E. (1981). Isolation and properties of a Bacillus subtilis mutant unable to produce fructose-bisphosphatase. $J$ Bacteriol 145, 760-767.

Fujita, Y. \& Fujita, T. (1983). Genetic analysis of a pleiotrophic deletion mutation ( $\Delta i g f)$ in Bacillus subtilis. J Bacteriol 154, 864-869.

Green, C. J., Stewart, G. C., Hollis, M. A., Vold, B. S. \& Bott, K. F. (1985). Nucleotide sequence of the Bacillus subtilis ribosomal RNA operon, rrnB. Gene 37, 261-266.

Itaya, M. (1992). Construction of a novel tetracycline resistance gene cassette useful as a marker on the Bacillus subtilis chromosome. Biosci Biotech Biochem 56, 685-686.

Itaya, M. (1993a). Stability and asymmetric replication of the Bacillus subtilis 168 chromosome. J Bacteriol 175, 741-749.

Itaya, M. (1993b). Integration of repeated sequences (pBR322) in the Bacillus subtilis 168 chromosome without affecting the genome structure. Mol \& Gen Genet 241, 287-297.

Itaya, M. (1993c). Physical mapping of multiple homologous genes in the Bacillus subtilis 168 chromosome: identification of ten ribosomal RNA operon loci. Biosci Biotech Biochem 57, 1611-1614.

Itaya, M. (1994). First evidence for homologous recombinationmediated DNA inversion of the Bacillus subtilis 168 chromosome. Biosci Biotech Biochem 58, 1836-1841.

Itaya, M. \& Tanaka, T. (1991). Complete physical map of the Bacillus subtilis 168 chromosome constructed by a gene-directed mutagenesis method. $J \mathrm{Mol} \mathrm{Biol} \mathrm{220,631-648.}$

Itaya, M., Laffan, J. J. \& Sueoka, N. (1992). Physical distance between the site of type II DNA binding to the membrane and oriC on the Bacillus subtilis chromosome. J Bacteriol 174, 5466-5470.
Jarvis, E. D., Cheng, S. \& Rudner, R. (1990). Genetic structure and DNA sequences at junctions involved in the rearrangements of Bacillus subtilis strains carrying the trpE26 mutation. Genetics 126, 785-797.

Kunst, F., Vassarotti, A. \& Danchin, A. (1995). Organization of the European Bacillus subtilis genome sequencing project. Microbiology 141, 249-255.

Liu, S.-L., Hessel, A. \& Sanderson, K. E. (1993a). Genomic mapping with I-CeuI, an intron-encoded endonuclease specific for genes for ribosomal RNA, in Salmonella spp., Escherichia coli, and other bacteria. Proc Natl Acad Sci US A 90, 6874-6878.

Liu, S.-L., Hessel, A. \& Sanderson, K. E. (1993b). The XbaIBlnI-CeuI genomic cleavage map of Salmonella typhimurium LT2 determined by double digestion, end labeling, and pulsed-field gel electrophoresis. J Bacteriol 175, 4104-4120.

Mandel, M. \& Higa, A. (1970). Calcium-dependent bacteriophage DNA infection. J Mol Biol 53, 159-162.

Maniatis, T., Fritsch, E. F. \& Sambrook, J. (1982). Molecular Cloning: a Laboratory Manual. Cold Springer Harbor, NY: Cold Spring Harbor Laboratory.

Marshall, P., Davis, T. B. \& Lemieux, C. (1994). The I-CeuI endonuclease: purification and potential role in the evolution of Chlamydomonas group I introns. Eur J Biochem 220, 855-859.

Miller, J. H. (1972). Experiments in Molecular Genetics. Cold Spring Harbor, NY: Cold Spring Harbor Laboratory.

Mueller, J. E., Bryk, M., Loizos, N. \& Belfort, M. (1993). Homing endonucleases. In Nucleases, 2 nd edn, pp. 111-143. Edited by S. M. Linn, R. S. Lloyd \& R. J. Roberts. Cold Spring Harbor, NY: Cold Spring Harbor Laboratory.

Ogasawara, N., Nakai, S. \& Yoshikawa, H. (1994). Systematic sequencing of the 180 kilobase region of the Bacillus subtilis chromosome containing the replication origin. $D N A$ Res 1, 1-14.

Ogasawara, N., Fujita, Y., Kobayashi, Y., Sadaie, Y., Tanaka, T., Takahashi, H., Yamane, K. \& Yoshikawa, H. (1995). Systematic sequencing of the Bacillus subtilis genome: progress report of the Japanese group. Microbiology 141, 257-259.

Rudner, R., Chevrestt, A., Buchholz, S. T., Studamire, B., White, A.-M. \& Jarvis, E. D. (1993). Two tRNA clusters associated with rRNA operons $r r n D$ and $r r n E$ in Bacillus subtilis. $J$ Bacteriol 175, 503-509.

Southern, E. M. (1975). Detection of specific sequences among DNA fragments separated by gel electrophoresis. J Mol Biol 98, 503-517.

Spizizen, J. (1958). Transformation of biochemically deficient strains of Bacillus subtilis by deoxyribonucleate. Proc Natl Acad S $i$ US A 44, 1072-1078.

Widom, R. L., Jarvis, E. D., Lafauci, G. \& Rudner, R. (1988). Instability of rRNA operons in Bacillus subtilis. J Bacteriol 170, 605-610.

Woese, C. R., Kandler, O. \& Wheelis, M. L. (1990). Towards a natural system of organisms: proposal for the domains Archaea, Bacteria, and Eucarya. Proc Natl Acad Sci USA 87, 4576-4579.

Yoshikawa, H. \& Wake, R. G. (1993). Initiation and termination of chromosome replication. In Bacillus subtilis and Other Gram-Positive Bacteria: Biochemistry, Physiology, and Molecular Genetics, pp. 507-528. Edited by A. L. Sonenshein, J. A. Hoch \& R. Losick. Washington, DC: American Society for Microbiology.

Received 30 December 1994; revised 11 April 1995; accepted 25 April 1995. 